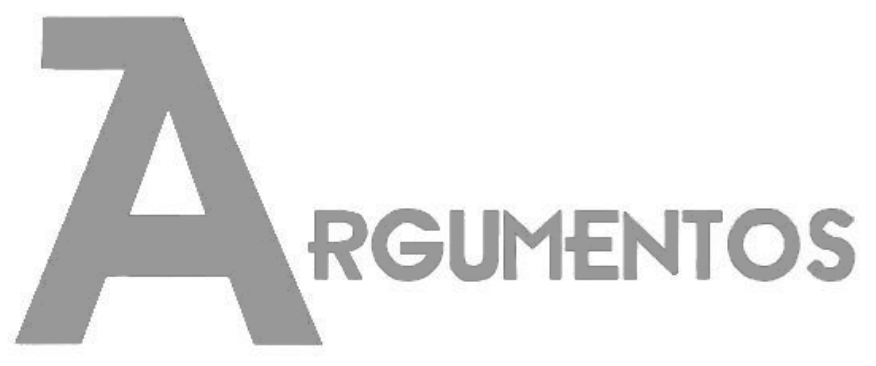

Vol. 18, n. 1, jan./jun. 2021 ISSN: 2527-2551 (online)

\title{
Percepção docente sobre a avaliação interna no ensino geral angolano
}

\author{
Balbina Uarinhenga ${ }^{1}$ \\ Rosenilton Silva de Oliveira²
}

Recebido em: 26/11/2020

Aprovado em: 10/02/2021

\begin{abstract}
Resumo: Neste texto reflete-se sobre os sentidos atribuídos pelo corpo docente à avaliação interna, no contexto da educação básica em Angola. Especificamente, a partir de entrevista realizadas com professores do I e II ciclos que atuam em escolas no município do Lubalo (Província da Lunda-Norte), busca-se compreender como esses agentes compreendem os processos avaliativos institucionais que visam aferir não o aprendizado em si do corpo discente, mas as ações da própria instituição escolar. Argumenta-se que no caso em tela, uma vez que o atual Sistema Geral de Ensino Angolano (cuja reforma deu-se em 2016) ainda está em processo de configuração e não conta com processo avaliativos institucionais definidos, os professores atribuem múltiplos sentidos ao ato de avaliar aproximando-o de uma lógica normativa de "inspeção" da prática docente.
\end{abstract}

Palavras-chave: avaliação institucional; ensino angola; política educacionais.

\section{Percepción docente de la evaluación interna en educación general en Angola}

Resumen: Este texto reflexiona sobre los significados atribuidos por la facultad a la evaluación interna, en el contexto de la educación básica en Angola. Específicamente, a partir de entrevistas con profesores de los ciclos I y II que trabajan en escuelas del municipio de Lubalo (Provincia Lunda -Norte), buscamos comprender cómo estos agentes entienden los procesos de evaluación institucional que tienen como objetivo evaluar no el aprendizaje en sí del cuerpo estudiantil, sino las acciones de la propia institución escolar. Se argumenta que en el caso que aparece a prueba, dado que el actual Sistema General de Educación de Angola (cuya reforma tuvo lugar en 2016) todavía está en proceso de configuración y no tiene un proceso de evaluación institucional definido, los profesores atribuyen múltiples significados al acto de evaluarlo acercando una lógica normativa de \&quot;inspección\&quot; de la práctica docente.

1 Pedagoga, mestra em educação pela Universidade Lueji A'Nkonde, Angola. E-mail: balbinawambauarinhenga950@gmail.com. ORCID: https://orcid.org/0000-0002-7368-3098.

${ }^{2}$ Antropólogo, docente na Universidade de São Paulo, Brasil. E-mail: rosenilton.oliveira@usp.br. ORCID: https://orcid.org/0000-0003-2952-4329. 
Palabras-clave: evaluación institucional; Enseñanza angoleño; política educativa.

\title{
Teacher perception on internal evaluation in Angolan General Education
}

\begin{abstract}
In this text we analyze on the meanings attributed by the faculty to internal evaluation, in the context of basic education in Angola. Specifically, from interviews with teachers from the I and II cycles working in schools in the municipality of Lubalo (Lunda-Norte Province), we seek to understand how these agents understand the institutional evaluation processes that aim to assess not the learning itself of the student body, but the actions of the school institution itself. It is argued that in the case on screen, since the current Angolan General Education System (whose reform took place in 2016) is still in the process of configuration and does not have a defined institutional evaluation process, teachers attribute multiple meanings to the act of evaluating it by approaching a normative logic of "inspection" teaching practice.
\end{abstract}

Keywords: institutional evaluation; Angolan teaching; educational policy.

\section{Introdução}

A avaliação institucional constitui o esforço dirigido pela gestão escolar com o propósito de verificar as metas riscadas, com a finalidade de corrigir o curso dos planos. Isto significa que cabe a ela possibilitar um diálogo constante entre os vários agentes no interior das escolas, de modo que a ação avaliativa se apresenta como uma atividade que integra a dinâmica da prática escolar (ZAU, 2019), uma vez que por meio dela é possível refletir sobre o que se faz, obtendo dados que auxiliarão a coordenação a compreender a situação e estabelecer as ações a serem realizadas.

Marcada pelo seu carácter processual, gradual e sua intencionalidade, a avaliação é um

o ato de gerir a dinâmica cultural da escola, afinada com as diretrizes e políticas educacionais públicas para a implantação de seu projeto políticopedagógico e compromisso com os princípios da democracia e com os métodos que organizem e criem condições para um ambiente educacional autónomo (soluções próprias, no âmbito de suas competências), de participação e compartilhamento (a tomada de decisões conjunta e a efetivação de resultados) e autocontrole (o acompanhamento e a avaliação com retorno das informações) (LUCK, 2009,p. 24).

Para além de medir a aprendizagem, por meio da avaliação institucional é possível aferir a qualidade do ensino dispensado numa determinada instituição à luz dos princípios e objetivos gerais estabelecidos para a educação escolar em determinado 
Artigos | Percepção docente sobre a avaliação interna no ensino geral angolano (UARINHENGA, Balbina; OLIVEIRA, Rosenilton Silva de)

contexto social. Para tanto, ela precisa ser integral de tal forma que respeite a complexidade do objeto a ser avaliado: a escola. Isto não significa dizer que a avaliação está isenta de juízo de valor, pelo contrário, ela o exige. Entretanto, tal julgamento, volta-se tanto para (sobre como se desenvolvem as ações) quanto para os resultados gerados o conjunto do sistema educativo e seus componentes com vistas a aprimorálos que a escola cumpra o seu papel social de formar cidadão emancipados, corrigir desigualdades e fomentar o saber científico.

Neste contexto, avalia-se primeiramente a estrutura, organização e funcionamento da escola; o currículo e seu desenvolvimento; o financiamento das escolas; para, me seguida, analisar o desempenho dos discentes, docentes e demais agentes escolares. Requer, portanto, um julgamento de valor que alimente a tomada de decisões dirigidas a melhoria dos níveis de qualidade e equidade da educação e o faça a partir de uma adequada leitura e análise macro e micro, assim como dos próprios atores do cenário educativo. Deste modo, ações punitivas não coadunam com o ato de avaliar, pelo contrário, a mudança

Nesse sentido Afonso (2007) considera a avaliação necessária para a mudança fundamental para as escolas eficazes, não como uma ação que busca punir os sujeitos, mas como atividade indutora de um movimento que produza a melhoria da escola nos seus próprios termos e à luz dos princípios que orientam a educação.

A possibilidade de oferecer uma educação de qualidade em cada escola se sustenta e depende de maneira importante na qualidade da gestão que realizam as administrações educativas. Em efeito, recaem nelas funções e responsabilidades pedagógicas, administrativas e financeiras essências para o bom funcionamento das instituições escolares e a qualidade dos resultados, tais como: a política de contratação dos docentes e gestores; a fixação de remunerações; a gestão, distribuição e uso de recursos; a supervisão e monitor da execução de programas educativos e sociais implementados nas escolas; as ofertas de formação contínua pertinentes; os sistemas de supervisão e apoio técnico pedagógico aos estabelecimentos, entre outros.

Ao aceitar a necessidade da gestão da mudança, reconhece-se que para sua realização se deverão ter em conta as funções que tipificam à gestão; quer dizer, o planejamento, a organização, a regulação ou execução e o controlo. Dito de outra 
Artigos | Percepção docente sobre a avaliação interna no ensino geral angolano (UARINHENGA, Balbina; OLIVEIRA, Rosenilton Silva de)

maneira, dirigir a mudança educativa significa planejá-la, organizá-la, regulá-la e controlá-la.

A formação de julgamentos de valor a respeito da maneira em que a escola consegue mudar no processo de seu desenvolvimento deve ter em conta o grau da mudança; quer dizer, deve-se julgar de maneira objetiva o que em um período de tempo é possível alcançar e que pode fixar-se, a priori, como etapa para a mudança, com suas metas. Se a mudança educativa tiver um caráter de processo, sua avaliação deverá ter em conta não somente quais resultados dele se derivam; mas sim, além disso, as ações que conduzem a esses últimos, quer dizer, o processo de mudança em si mesmo. A avaliação do processo permite a tomada de decisões no momento oportuno para introduzir as correções que sejam necessárias e assegurar, com isso, o cumprimento das metas e objetivos expostos (resultados).

Para Marinelli (2013) é indiscutível que o centro das reais mudanças educativas transcorre principalmente na escola; portanto, as principais ações da gestão da mudança devem orientar-se para a escola, para as estruturas de gestão e para os fatores da comunidade que interatuam com a instituição, já que, se estes não se envolvem na transformação e não a compreendem bem, o esforço da escola fica limitado.

Durante a investigação, a autora pôde constatar que existe uma tendência a avaliar resultados e não o processo de mudança em todas suas arestas. Por exemplo, dá-se muita ênfase aos resultados da aprendizagem, buscando-se neles a eficiência ou não do processo de transformações. Mas, se tivermos em conta as dimensões antes mencionadas (contextos, insumos, processos e resultados, incluindo o seguimento ou impacto), pode-se ter julgamentos de valor da mudança de um enfoque sistémico, que permite penetrar mais profundamente nas origens e causas do fenómeno, permitindo resolver os problemas que na prática vão apresentando-se.

O reconhecimento da necessidade de avaliar o processo de mudança é o que faz mais pertinente a ideia de incluir o trabalho das instituições educacionais, a avaliação interna como componente indissolúvel da gestão educacional e campo da presente investigação. Por meio da avaliação interna é possível obter informação sistemática e atualizada a respeito do que acontece em uma instituição por seus próprios atores, os membros da comunidade educativa escolar, que são, em definitiva, os mais 
Artigos | Percepção docente sobre a avaliação interna no ensino geral angolano (UARINHENGA, Balbina; OLIVEIRA, Rosenilton Silva de)

comprometidos com as mudanças e os que mais conhecem do que realmente ocorre no contexto em que se desenvolvem.

A partir deste quadro, neste texto reflete-se sobre os sentidos atribuídos pelo corpo docente à avaliação interna, no contexto da educação básica em Angola. Especificamente, a partir da revisão da bibliografia e análise de entrevistas ${ }^{3}$ realizadas com professores da educação básica (primário, primeiro e segundo ciclo) que atuam em escolas no município do Lubalo (Província da Lunda-Norte), busca-se compreender como esses agentes compreendem os processos avaliativos institucionais que visam aferir não o aprendizado em si do corpo discente, mas as ações da própria instituição escolar.

Como se verá mais adiante, foram entrevistados seis docentes (sendo uma mulher e cinco homens) tendo por base um roteiro semiestruturado. A amostra qualitativa tanto das escolas, quanto dos profissionais, foi realizada tendo em conta do contexto do município do Lubalo.

Situado no centro da Lunda-Norte, há cerca de $400 \mathrm{~km}$ de distância da capital da província, Dundo, e quase $1 \mathrm{mil}$ km de Luanda, Lubalo é um município com cerca de 21 mil habitantes, sendo que dois terços vivem na sede do município, enquanto 5.029 pessoas residem na Comuna do Luangue e 2.684 na Comuna do Muvulegi. Isto faz com que Lubalo registre o menor número de residentes com $2 \%$ da população da província (Angola, 2016).

Estão controlados a nível do município 257 autoridades tradicionais ${ }^{4}$, sendo 24 regedores, 130 sobas, 102 sobetas e 1 rainha, integrados em 69 aldeias (Quadro 1)

\footnotetext{
${ }^{3}$ As entrevistas foram realizadas no contexto de uma pesquisa mais ampla, que integra o mestrado de Balbina Uarinhenga (2020), realizado na Universidade Lueji $A^{\prime} N k o n d e$, sobre a avaliação institucional como instrumento de gestão estratégica em educação.

${ }^{4}$ A Constituição da República de Angola promulgada em 2010, reconhece "o papel e as funções das intuições do poder tradicional constituídas de acordo com o direito consuetudinário" (art. 223) e suas formas de constituições. Na região da Lunda, o poder tradicional é exercido hierarquicamente por regedores, sobetas, sobas e pela rainha; sendo que cada um deles exerce sua influência sobre porções específicas do território. Sobre o tema ver Manassa (2011).
} 
Artigos | Percepção docente sobre a avaliação interna no ensino geral angolano (UARINHENGA, Balbina; OLIVEIRA,

Quadro 1: Autoridades do município do Lubalo

\begin{tabular}{|l|c|c|c|c|c|}
\hline Localidades & Regedores & Sobas & Sobetas & Rainhas & Aldeias \\
\hline Sede & 11 & 78 & 54 & 1 & 29 \\
\hline Comuna do Luangue & 8 & 32 & 33 & 0 & 22 \\
\hline Comuna do Muvulegi & 5 & 20 & 15 & 0 & 18 \\
\hline Total & 24 & 130 & 102 & 1 & 69 \\
\hline
\end{tabular}

Fonte: Relatório Administração Municipal do Lubalo (LUBALO, 2017)

Em Lubalo, a gestão da rede escolar é assegurada pela respectiva Direção Municipal da Educação (DME), um serviço desconcentrado da Administração Municipal, de que depende orgânica, administrativa e funcionalmente (Lei no. 17/10, p. 1585). Esta tripla dependência, no entanto, não exclui a subordinação programática em relação à Direção Provincial da Educação de Lunda-Norte, que, por seu turno, procede em conformidade com as diretrizes baixadas pelo Ministério da Educação, órgão máximo de tutela do sistema nacional de ensino. Atualmente, a Direção Municipal de Educação, conta com: Diretor Municipal, Chefe de Secção de Ensino, Ciências, Tecnologia e inovação, Chefe de planeamento, Estatística e Recursos Humanos, Chefe de Secção de Inspeção, Chefe de Secretária e a Secção de Assuntos Laborais.

De acordo com a Lei no 17/2016, o sistema de educação angolana está organizado da seguinte forma:

- Ensino primário: equivale ao Fundamental 1 no Brasil, atende crianças de seis a 11 anos e está subdividido em seis classes, cada uma delas correspondendo a um ano de estudo;

- Ensino secundário: subdivido em I e II ciclos, corresponde as etapas brasileiras do Fundamental II e Ensino Médio, respectivamente. O I Ciclo comporta três classes (da sétima à nona, 12 a 14 anos)) enquanto o II Ciclo está divido entre PUNIV (liceu) e o ensino médio técnico, frequentado por jovens de 15 a 18 anos. 
Artigos | Percepção docente sobre a avaliação interna no ensino geral angolano (UARINHENGA, Balbina; OLIVEIRA, Rosenilton Silva de)

A rede escolar do Lubalo é constituída por 52 escolas; delas, 49 escolas de ensino primário, 2 escolas do I ciclo de Ensino Secundário e 1 escola do II Ciclo de Ensino Secundário.

Se, do ponto de vista demográfico há certo equilíbrio entre homens e mulheres (10.131 e 10.500, respectivamente), o quadro docente não reproduz esta divisão de forma equânime: em média, o corpo docente é composto por $80 \%$ de homens, contra $20 \%$ de mulheres, em todos os níveis de ensino.

A escolha do campo empírico de observação deu-se por conveniência (PATTON, 1980), isto é, a seleção das escolas baseou-se em critérios que assumem tanto um caráter pragmático quanto teórico. Deste modo, considerando que a realidade das escolas referenciadas faz parte da convivência diária de uma das autoras, que atua como professora do II ciclo do ensino secundário, ela foi selecionada como unidade-chave.

A partir da unidade-chave, elegeu-se as duas escolas circunvizinhas, (do ensino primário e I ciclo do ensino secundário), uma vez que há um trânsito frequente entre discentes e docentes entre estas três instituições. O Quadro 2, que segue, apresenta uma breve caracterização das escolas onde foi aplicada a pesquisa de campo. 
Artigos | Percepção docente sobre a avaliação interna no ensino geral angolano (UARINHENGA, Balbina; OLIVEIRA, Rosenilton Silva de)

Quadro 2: Caracterização das escolas pesquisadas - Lubalo/Lunda-Norte

\begin{tabular}{|c|c|c|c|c|c|c|c|}
\hline Nível de Ensino & \multicolumn{2}{|l|}{ Primário } & \multicolumn{2}{|c|}{ I ciclo do ensino Secundário } & \multicolumn{3}{|c|}{ II ciclo do ensino secundário } \\
\hline Município & \multicolumn{2}{|c|}{ Lubalo/L. Norte } & \multicolumn{2}{|c|}{ Lubalo/L. Norte } & \multicolumn{3}{|c|}{ Lubalo/L. Norte } \\
\hline Fundação & \multicolumn{2}{|l|}{2010} & \multicolumn{2}{|l|}{2009} & \multicolumn{3}{|c|}{2014} \\
\hline Nível de ensino & \multicolumn{2}{|l|}{ Primário } & \multicolumn{2}{|c|}{ I Ciclo } & \multicolumn{3}{|c|}{ II ciclo } \\
\hline $\begin{array}{c}\text { Classe que } \\
\text { lecciona }\end{array}$ & \multicolumn{2}{|c|}{ Iniciação a 6a classe } & \multicolumn{2}{|c|}{ 7a, 8 a e 9a Classes } & \multicolumn{3}{|c|}{$10^{\mathrm{a}}, 11^{\mathrm{a}}$ e $12^{\mathrm{a}}$ classes } \\
\hline $\begin{array}{c}\text { Zona } \\
\text { Geográfica }\end{array}$ & \multicolumn{2}{|c|}{ Suburbana } & \multicolumn{2}{|c|}{ Suburbana } & \multicolumn{3}{|c|}{ Quadro domiciliar Urbana } \\
\hline № de salas & \multicolumn{2}{|l|}{10} & \multicolumn{2}{|l|}{8} & \multicolumn{3}{|c|}{3} \\
\hline № de turmas & \multicolumn{2}{|l|}{20} & \multicolumn{2}{|l|}{16} & \multicolumn{3}{|c|}{6} \\
\hline № de turnos & \multicolumn{2}{|l|}{2} & \multicolumn{2}{|l|}{2} & \multicolumn{3}{|c|}{2} \\
\hline $\begin{array}{c}\text { № de alunos } \\
\text { por sala }\end{array}$ & \multicolumn{2}{|l|}{51} & \multicolumn{2}{|l|}{27} & \multicolumn{3}{|c|}{23} \\
\hline \multirow{2}{*}{ Total de alunos } & \multirow{2}{*}{1.039} & $\mathrm{~F}$ & \multirow{2}{*}{336} & $\mathrm{~F}$ & \multirow{2}{*}{138} & $M$ & $\mathrm{~F}$ \\
\hline & & 535 & & 163 & & 106 & 32 \\
\hline \multicolumn{8}{|c|}{ Quadro pessoal } \\
\hline Diretor & 1 & & 1 & & & 1 & \\
\hline Subdiretor & 1 & & 2 & & & 2 & \\
\hline Coordenadores & 9 & & 17 & & & 22 & \\
\hline Professores & 19 & & 35 & & & 51 & \\
\hline Pessoal adm. & 6 & & 6 & & & 6 & \\
\hline Pessoal auxiliar & 6 & & 4 & & & 9 & \\
\hline $\begin{array}{l}\text { Pessoal } \\
\text { operário }\end{array}$ & 6 & & 4 & & & 9 & \\
\hline
\end{tabular}

Fonte: Direção Municipal da Educação, 2020.

A Escola do ensino Primário Ngangula no 218, situa-se no Município do Lubalo, Província da Lunda-Norte. A estrutura arquitetônica da escola é de carácter definitiva, constituída por 10 salas, 1gabinete e 1 secretaria; também possui 4 casas de banho para professores e alunos e 1jardim. A escola matriculou, em 2020, 1.039 alunos, dos quais 
Artigos | Percepção docente sobre a avaliação interna no ensino geral angolano (UARINHENGA, Balbina; OLIVEIRA, Rosenilton Silva de)

504 do género masculino e 535 do género feminino, subdivididos em 20 turmas, em turno diurno (manhã e tarde), sendo 51 alunos em cada sala.

A escola possui um quadro pessoal composto por 1 diretor, 1 subdiretor, 9 coordenadores, 1 chefe de secretaria, 19 professores, 6 pessoal administrativo, 6 pessoal auxiliar e 6 pessoal operário, totalizando 48 trabalhadores.

A maioria dos professores são homens e só $17,4 \%$ são mulheres; $87 \%$ dos professores têm entre 6 e 20 anos de serviço na educação.

A Escola do I ciclo do ensino secundário no 229, colégio 4 de Abril, é de construção definitiva e possui 8 salas de aulas. Lecciona-se as seguintes classes: 7ạ , 8a e 9a classe. Em 2020, a escola atendeu 436 alunos, distribuídos em 1 turno diurno, isso é, manhã e tarde, e em 16 turmas constituídas por 27 alunos em cada sala, 1 gabinete, 1sala de professores e instalação sanitárias masculinas e femininas. A escola não possui cantina, refeitório e biblioteca. Não existe também um campo específico para a educação física: essas aulas são ministradas ao redor da escola, o que pode dificultar o ensino e aprendizagem dos alunos. O quadro pessoal é constituído por 1 diretor, 2 subdiretores, 17 coordenadores, 1 chefe de secretaria, 34 professores, 6 pessoal administrativo, 4 pessoal auxiliar, e 4 pessoal operário, totalizando 69 trabalhadores. Quando à formação académica, a escola tem um professor licenciado, 9 bacharéis e 24 professores com o ensino médio. A maioria dos professores são homens, e só $9.7 \%$ são mulheres. Os professores da instituição têm entre 6 e 15 anos de serviços na educação. A maior parte dos alunos são do género masculino, sendo 700 alunos do género masculino e 380 do género feminino, perfazendo assim o total de 1.080 alunos.

A secretaria é um órgão auxiliar da diretoria na administração da instituição escolar. O secretário atualiza toda a documentação da escola.

A escola do II ciclo do ensino Secundário do Lubalo, comporta uma estrutura arquitetônica de carácter definitiva constituída por 03 salas, 06 turmas, distribuídas em 1turno (manhã e tarde); os alunos estão distribuídos em número de 23 por cada sala de aula, totalizando, nesse caso, 138 alunos matriculados, dos quais 32 do género feminino.

O quadro pessoal é composto por 1 diretor, 2 subdiretores, 22 coordenadores, 2 chefes de secretaria, 49 professores, 6 pessoal administrativo, 9 pessoal auxiliar e 9 pessoal operário, totalizando 99 trabalhadores. A maioria dos professores são homens e só $13 \%$ são mulheres. Na escola do II ciclo do ensino secundário, a maioria dos 
Artigos | Percepção docente sobre a avaliação interna no ensino geral angolano (UARINHENGA, Balbina; OLIVEIRA, Rosenilton Silva de)

professores são licenciados e $45.2 \%$ têm pouca experiência no que tange à função que exercem. A maioria dos alunos é do género masculino.

A Direção do Lubalo teve uma baixa concernente à recepção de novos alunos para o Il ciclo do ensino secundário geral. Isto, deveu-se a questão da instituição ser um PUNIV. Pela atual política de emprego, principalmente no sector da educação, somente é aceite quem teve a formação de professores. Isso fez com que houvesse baixo número de alunos no ano letivo de 2020.

A escola apresente uma estrutura física em bom estado de conservação, com quadros e carteiras; porém, não tem biblioteca, sala de informática e quadra para as aulas de educação física.

Foram entrevistados os 3 diretores do ensino geral: o diretor do ensino primário, o diretor do I ciclo e o diretor do II ciclo do ensino secundário, além de 6 professores, sendo 2 do ensino primário; 2 do I ciclo e 2 do II ciclo do ensino secundário, todos da sede municipal do Lubalo, província da Lunda-Norte.

Quadro 3: Atuação docente

\begin{tabular}{|c|c|c|c|c|c|c|c|}
\hline \multirow{2}{*}{ Instituições } & \multicolumn{2}{|c|}{ Docente $^{5}$} & \multirow[t]{2}{*}{ Doc } & \multirow{2}{*}{ Idade } & \multirow{2}{*}{$\begin{array}{c}\text { Tempo de } \\
\text { Serviço }\end{array}$} & \multirow{2}{*}{$\begin{array}{l}\text { Carga } \\
\text { horária }\end{array}$} & \multirow{2}{*}{$\begin{array}{l}\text { Formação } \\
\text { Académica }\end{array}$} \\
\hline & $\mathrm{F}$ & $M$ & & & & & \\
\hline $\begin{array}{l}\text { Escola do Ensino } \\
\text { Primário }\end{array}$ & & $A$ & & 24 & $\begin{array}{l}2 \text { Anos } \\
3 \text { Anos }\end{array}$ & $24 \mathrm{~h}$ & Ensino Médio \\
\hline Escola do I Ciclo & & C & & 27 & 7 Anos & $24 \mathrm{~h}$ & $\begin{array}{l}\text { Bacharel } \\
\text { Licenciado }\end{array}$ \\
\hline Escola do II Ciclo & $E$ & $F$ & & 32 & $\begin{array}{l}2 \text { Anos } \\
12 \text { Anos }\end{array}$ & $24 \mathrm{~h}$ & $\begin{array}{l}\text { licenciado } \\
\text { Licenciada }\end{array}$ \\
\hline
\end{tabular}

Fonte: elaborada pela autora a partir dos dados coletados em entrevistas.

\footnotetext{
${ }^{5}$ Os nomes dos/a docentes entrevistados/a foram substituídos por letras. Deste modo, p. ex. a letra E, corresponde a uma mulher, de 32 anos de idade, licenciada, com 2 anos de atuação no ensino.
} 
Artigos | Percepção docente sobre a avaliação interna no ensino geral angolano (UARINHENGA, Balbina; OLIVEIRA, Rosenilton Silva de)

Conforme apontou-se acima, dentre os professores entrevistados, 5 são homens e 1 uma mulher. Encontram-se nas faixas etárias de 24 a 44 anos de idade. Os professores têm um nível de estudo indicado na legislação (Lei no 17/16) para os ciclos em que atuam: magistério em nível médio (para o ensino primário) e graduação para os I e II ciclos. Entretanto, conforme indicaram nas entrevistas, para além dos seminários de atualização pedagógica ofertadas pelo Estado, não realizaram outros cursos de formação continuada ou de especialização.

Quanto ao aspecto da formação inicial e continuada de professores em Angola, é preciso sempre contextualizar o momento social e político em que o país se encontra. Conforme demostra Ermelinda Liberato (2014), a primeira universidade será criada em 1968, a partir das instituições de Estudos Gerais Universitários de Angola e Moçambique ${ }^{6}$.

Até ao início da década de 1960, Angola não dispunha de nenhuma instituição de ensino superior no seu território. Para a frequência desse nível de ensino, os estudantes tinham de se deslocar a Portugal. No entanto, apesar de serem atribuídas bolsas de estudo para a frequência do ensino superior na metrópole, o fato é que esse acesso estava vedado à maioria dos angolanos. Os custos incomportáveis relacionados com a deslocação e manutenção desses estudantes na metrópole afastavam a maioria dos candidatos ao ensino universitário, daí que "entre 1833 e 1857 estudassem na Europa apenas 19 estudantes angolanos" (Santos, 1970, p. 117), um número muito reduzido para as reais necessidades do país. (LIBERATO, 2014, p.1012)

Após a independência, o ensino superior será reformulado: a Universidade de Luanda dá origem a Universidade de Angola e, em 1985 à Universidade Agostinho neto (UAN), em homenagem ao primeiro presidente do país. É somente após o fim da guerra civil, que perdurou até 2002 , que se observa um aumento significativo no número de instituições de ensino superior (LIBERATO, 2014).

Conforme apresenta Samuel Carlos Victorino (2012), até os anos 2008, a UAN era a única universidade pública do país e dispunha de 40 faculdades localizadas nas principais cidades do país. Com a publicação do Decreto 05/2009, há um desmembramento da UAN e a criação de 7 Regiões Acadêmicas (cada uma delas compreendendo um conjunto de provinciais), nas quais foram alocadas universidades

\footnotetext{
${ }^{6}$ Sobre o processo de estabelecimento do ensino superior em angola ver Juliana Izar (2018).
} 
Artigos | Percepção docente sobre a avaliação interna no ensino geral angolano (UARINHENGA, Balbina; OLIVEIRA, Rosenilton Silva de)

específicas, o que significou também a expansão no número de vagas (VICTORINO, 2012, p. 14).

Quadro 4: Distribuição das universidades por Região Acadêmica

\begin{tabular}{|l|l|}
\hline \multicolumn{1}{|c|}{ Região Académica (RA) e suas províncias } & \multicolumn{1}{c|}{ Nome da Universidade } \\
\hline RA I - Províncias: Luanda e Bengo & Universidade Agostinho Neto \\
\hline RAll - Províncias: Benguela e Kwanza Sul & Universidade Katyavala Buila \\
\hline RA III - Províncias: Zaire e Cambinda & ) Universidade Onze de Novembro \\
\hline RA IV - Províncias: Lunda Norte, Lunda Sul e Malanje & Universidade Lueji A'Nkonde \\
\hline RA V - Províncias: Huambo, Bié e Moxico & $\begin{array}{l}\text { Universidade José Eduardo dos } \\
\text { Santos }\end{array}$ \\
\hline RA VI - Províncias: Huíla, K. Kubango, Namibe e & Univ. Mandume ya Ndemufayo \\
\hline RAnene & Universidade Kimpa Vita \\
\hline
\end{tabular}

Fonte: Victorino, 2012, p. 14.

Uma vez que para exercer a docência no II Ciclo, exige-se formação em nível superior, observa-se a concentração de professores com maior tempo de regência atuando neste nível. É preciso destacar também que o ensino técnico e profissionalizante também é ministrado neste ciclo. Na amostra selecionada para esta pesquisa, selecionou-se: 3 docentes em início de carreira (menos de 5 anos de atuação) e 3 professores com mais experiência em sala de aula (acima de 7 anos). Esta escolha, que não acompanha necessariamente o recorte etário, visou a apreender as múltiplas visões desses profissionais sobre avaliação, tendo em conta a sua trajetória de formação e exercício do magistério.

\section{Percepção docente sobre avaliação institucional}

Uma vez que o objetivo da pesquisa não era aferir o grau de conhecimento dos profissionais quanto a normativa educacional ou debate pedagógico sobre a avaliação institucional, as questões disparadoras do entrevistas tinham resposta abertas, possibilitando a livre expressão das pessoas entrevistadas. Foram respeitados os 
Artigos | Percepção docente sobre a avaliação interna no ensino geral angolano (UARINHENGA, Balbina; OLIVEIRA, Rosenilton Silva de)

princípios do código de ética em pesquisa em Ciências humanas e a identidade da/dos entrevistada/os foram preservadas. Cada entrevista foi realizada individualmente.

Após a coleta dos dados relativos à trajetória acadêmica, perguntou-se genericamente: "para que serve a avaliação?". Esta pergunta disparadora, sobre a função do ato avaliativo tinha como objetivo central, compreender como docentes compreendem tal ação e como a relacionam mnemonicamente à sua prática e ao próprio sistema de ensino.

- A avaliação serve para diagnosticar o nível cognitivo do aluno (Docente A do Ensino Primário);

- A avaliação institucional tem a ver com o comportamento, a presença, a forma como o trabalhador exerce a sua atividade, a ética e a deontologia profissional (Docente B do Ensino Primário);

- A avaliação institucional tem grande importância porque tem por fim melhorar as falhas (Docente $\mathrm{C}$ do I Ciclo);

- A avaliação é importante porque serve para diagnosticar (Docente D do I Ciclo);

- A avaliação serve para medir o nível do aprendizado (Docente E do II Ciclo);

- A avaliação começa com os professores, mas até hoje os professores e alunos não aparecem na escola (Docente $\mathrm{F}$ do II Ciclo).

Interessante perceber que, apesar das respostas apontarem para diferentes sujeitos da avaliação (estudantes e docentes), elas convergem na perspectiva de que a ela "serve" como um instrumento de diagnóstico com vistas a imprimir uma mudança na atitude dos sujeitos. Chama a atenção o fato que não aparece nas falas os órgãos e instituições escolares enquanto entes passíveis de medição, mesmo quando o Docente $C$ indica que "A avaliação institucional tem grande importância porque tem por fim melhorar as falhas (Docente C do I Ciclo)".

Os professores entrevistados reconhecem o valor da avaliação, servindo de diagnóstico, sobretudo do processo de ensino-aprendizagem, sobretudo de modo comparativo (início e término do alo letivo) com vistas a aferir o "quanto" se aprendeu.

Há, nesta lógica de avaliação, certa ideia de avanço linear ascendente, em que o aprendiz parte de um ponto " $x$ " e deve, necessariamente, mover-se até " $y$ ". Obviamente que o ato de educar é transformador (FREIRE, 2000), entretanto, mudar não é necessariamente sinônimo de evoluir, no sentido de partir de um grau mais baixo para 
Artigos | Percepção docente sobre a avaliação interna no ensino geral angolano (UARINHENGA, Balbina; OLIVEIRA, Rosenilton Silva de)

um mais elevado, pode significar transformação de valores, visão de mundo e engajamento social.

Instados/a a falar especificamente sobre avaliação institucional, aparece de forma patente os múltiplos sentidos que o termo evoca:

- A avaliação institucional tem a ver com o comportamento, na desordem e na ordem (Professores A do Ensino Primário);

- A avaliação institucional depende de cada instituição, de como a própria tem avaliado os seus funcionários (Professores B do Ensino Primário);

- A avaliação é necessária para medir os conhecimentos adquiridos ao longo do ano (Professores C do I Ciclo);

- A avaliação institucional é para avaliar a instituição em si (Professores D do I Ciclo);

- A avaliação institucional tem grande importância no domínio na qual cada funcionário deve ser avaliado para se descobrir os pontos fracos e fortes, para melhorar nos próximos anos (Professores E do II Ciclo);

- Eu penso que a avaliação institucional serve para avaliar os professores e escolas (Professores F do II Ciclo).

Com exceção da Docente C, que eles atrelou o termo "avaliação institucional" a ação de aferir a aprendizagem do corpo discente a partir de instrumentos (oficiais ou não) elaborado fora do contexto de sala de aula, os demais docentes compreendem este ato como uma análise dos profissionais que atuam nas escolas (professore/as e funcionários) e a própria unidade escolar.

De fato, a avaliação institucional, é uma ação contínua que compromete-se com o aprimoramento de todos na aprendizagem e com a transformação institucional, partindo de uma prática participativa com toda a comunidade escolar (e não só); estando a avaliação inserida no projeto educacional, coloca em prática o Plano Institucional, as finalidades da educação e as concepções pedagógicas (VASCONCELLOS, 1998). 
Artigos | Percepção docente sobre a avaliação interna no ensino geral angolano (UARINHENGA, Balbina; OLIVEIRA, Rosenilton Silva de)

Neste diapasão, os/a professores/a entrevistados/a indicam que a avaliação institucional possui uma face interna (executada pelos diretores das escolas) e outra externa (realizada por inspetores atrelados ao departamento provincial de educação):

- A avaliação interna é diferente da avaliação externa, porque a avaliação interna é feita pelos diretores e a externa pelos inspetores (Professores B do Ensino Primário);

- A diferença entre a avaliação interna e externa, é que, a interna é feita pelo Diretor e a externa pela inspeção (Professores D do I Ciclo);

- Há diferença entre a avaliação interna e externa, porque a avaliação interna é feita pelos superiores da instituição e a externa pelas pessoas que vêm de fora (Professores F do II Ciclo).

Em síntese, tanto a avaliação interna quanto a externa estariam relacionadas, "porque o professor deve ser avaliado pela comunidade" (Professores C do I Ciclo). Ou ainda, como uma forma de analisar a "vida social da pessoa" (Professores E do II Ciclo).

É interessante notar a mudança de entendimento, por parte desses/a docentes, sobre o papel da avaliação institucional quando confrontadas com a sua forma de realização (interna ou externamente à unidade escolar). Se, num primeiro momento, compreendia-se que o ato institucional deveria analisar a instituição, no seu processo de efetivação volta-se para a prática docente, como se houve uma cadeia hierárquica. Esta lógica é, inclusive, enunciada pela Docente A do ensino primário: "A avaliação da unidade escolar é feita pelos diretores e nós os professores avaliamos os alunos".

Instados/a a comentar sobre este processo de avaliação e os instrumentos utilizados reportam ao trabalho da supervisão (inspeção) escolar sobre o cumprimento das rotinas administrativas e não propriamente à atividade reflexiva sobre as práticas pedagógicas e da gestão democrática:

- A avaliação da unidade escolar é feita pelos membros da instituição escolar (Professores B do Ensino Primário);

- A avaliação de uma unidade escolar consiste em garantir o padrão de qualidade da aprendizagem por meio dos serviços prestados (Professores $\mathrm{C}$ do I Ciclo);

- A avaliação da unidade escolar é o meio pelo qual a inspeção verifica o andamento da instituição escolar (Professores D do I Ciclo); 
Artigos | Percepção docente sobre a avaliação interna no ensino geral angolano (UARINHENGA, Balbina; OLIVEIRA, Rosenilton Silva de)

- A avaliação da unidade escolar é feita através da matéria, mas avisa-se para o aluno e professor prepararem-se (Professores E do II Ciclo);

- A avaliação da unidade escolar é feita através das fichas, são avaliados os chefes e os professores (Professores F do II Ciclo).

Não se trata aqui de inferir que o corpo decente angolano desconhece processos avaliativos institucionais ou que "confundem" aferição do ensino e da aprendizagem com a análise do sistema educacional. Destaca-se, tão somente, que as falas revelam o que ser observa na prática: o Sistema Geral de Ensino ainda não possui instrumentos avaliativos que permitam analisar as instituições escolares de modo orgânico, seja interna ou externamente. As ações restringem-se à verificação sobre o cumprimento dos dispositivos legais e programas de ensino.

Neste sentido é que, quando questionados/a sobre quais seriam os melhores instrumentos para a realização da avaliação, as respostas voltam-se para as estratégias desenvolvidas em sala de aula, por cada docente com seus estudantes:

- Os instrumentos para avaliar são o professor e os alunos; o instrumento mais importante é o aluno. Para avaliar o aluno aplica-se a prova oral, escrita e velar pelo comportamento (Professores A do Ensino Primário);

- Os instrumentos para a avaliação são a prova oral e a prova escrita (Professores A do Ensino Primário);

- Quanto aos instrumentos para esta avaliação é o relatório (Professores C do I Ciclo);

- O instrumento para a avaliação é a dedicação (Professores D do I Ciclo);

- Quanto aos instrumentos utilizados são os manuais (Professores E do II Ciclo);

- Os melhores instrumentos, tudo dependem do avaliador, para ele o melhor seria a presença do avaliador (Professores F do II Ciclo).

No que tange a atuação docente em sala de aula, as ações da supervisão escolar são compreendidas pelos/a professores/a entrevistados/a como um instrumento importante na tomada de decisões com vistas à melhoria de suas práticas pedagógicas, como expressa o Docente E do II Ciclo: “A inspeção da escola é muito boa por auxiliar 
Artigos | Percepção docente sobre a avaliação interna no ensino geral angolano (UARINHENGA, Balbina; OLIVEIRA, Rosenilton Silva de)

todos os professores no trabalho". Por outro lado, esta melhoria pode estar associada a uma preocupação em ser mal avaliado: "A inspeção ajuda-nos a ensinar bem, porque eles nos avaliam e assim os professores preocupam-se sempre"(Professores F do II Ciclo), de modo que ela pode ser percebida não como uma atitude indutora de boas práticas, mas como um ato persecutório.

Esta percepção do corpo docente, embora revele uma contradição aparente (no sentido de que, por um lado, reconhece a importância da ação da inspetoria na consecução dos objetivos dos programas educacionais e, por outro, seu papel cerceador da ação docentes, que tendem a tão somente seguir os manuais), ela parece corroborar o que prevê a Lei 17/16, sobre a atuação dos inspetores:

A inspeção do Sistema de Educação e Ensino consiste no controlo, na fiscalização e na verificação da conformidade das condições de organização e gestão dos dispositivos educativos e do funcionamento das instituições de ensino e das demais estruturas do Sistema de Educação e Ensino, em função das orientações e das normas estabelecidas"(Lei 17/16, art. .117, 1)

Não se trata aqui de opor o papel da avaliação institucional e da inspeção ou ainda estabelecer algum tipo de hierarquia entre essas duas práticas, mas destacar seus aspectos complementares. Neste aspecto, por um lado é necessário produzir um novo sentido à supervisão escolar (FIALHO; NOBREGA, 2016) e desenvolver ações avaliativas sistemáticas capazes de auxiliarem os agentes escolares (docentes e dirigentes) a aperfeiçoarem suas práticas pedagógicas.

É significativo que essa aproximação entre inspeção escolar e avaliação institucional do desempenho docente apareçam de modo conjugado na fala dos professores entrevistados, ao serem questionados sobre o processo de aferição de desempenho dos profissionais da escola, ao mesmo tempo em que os docentes veem reproduzido sobre si a mesma lógica desenvolvida com os alunos:

- A avaliação de desempenho de professores efetua-se através de provas orais, escritas e prática (Professores A do Ensino Primário);

- Os professores avaliam os alunos (Professores B do Ensino Primário);

- É o diretor que avalia os professores (Professores C do I Ciclo); 
Artigos | Percepção docente sobre a avaliação interna no ensino geral angolano (UARINHENGA, Balbina; OLIVEIRA, Rosenilton Silva de)

- A avaliação de desempenho dos professores é feita através das fichas (Professores D do I Ciclo);

- A avaliação de desempenho é feita pela inspeção municipal (Professores E do II Ciclo);

- A avaliação de desempenho é feita através da ficha de avaliação, onde o diretor avalia a qualidade do trabalho, a pontualidade, as relações humanas e 0 aperfeiçoamento profissional (Professores F do II Ciclo).

Percebe-se que há uma lógica hierárquica no processo avaliativo, conforme apontamos acima, que impede um exercício de auto avaliação (individual ou coletiva). Ao apontarem para os instrumentos utilizados por diretores na análise do desempenho docente, revela-se mais um caráter de normalizador (no sentido de regular a ação pedagógica) do que sua criatividade. Este aspecto ganha realce quando se observa o processo de devolutiva do resultado das avaliações que são feitas sobre trabalho de professor:

- A devolutiva da avaliação, eu me preparo procuro melhorar os meus alunos para não terem medo com o professor sendo este mediador, o professor é o centro (Professores A do Ensino Primário);

- Quando o diretor avalia, entrega a ficha ao professor para esse assinar (Professores A do Ensino Primário);

- A devolutiva da avaliação é feita no fim do ano letivo e entregam aos professores, mas se atingir a nota 12 , o avaliado tem que preocupar-se para melhorar (Professores $\mathrm{C}$ do I Ciclo);

- Nunca teve o resultado das suas avaliações (Professores D do II Ciclo);

- A devolutiva da avaliação contribui para a formação, mas não tem havido resposta por parte do Ministério (Professores E do II Ciclo);

- A devolutiva dos resultados das avaliações é feita através dos modelos de avaliação. Por sua vez, o diretor chama o professor para assinar, mas antes, o professor tem o direito de reclamar (Professores F do II Ciclo). 
Artigos | Percepção docente sobre a avaliação interna no ensino geral angolano (UARINHENGA, Balbina; OLIVEIRA, Rosenilton Silva de)

Ao fim da avaliação de desempenho, os docentes são confrontados com uma "nota" que indica o grau de aproximação das metas estabelecidas. Nota-se aqui a mesma lógica métrica utilizada na aferição da aprendizagem do corpo docente. Se por um lado a nota (número ou letra) pode ser um signo distintivo de práticas desenvolvidas num determinado período, por outro, ele pode operar de modo deletério caso não sejam escrutinados os fatores que as condicionaram. De todo modo, este método de aferição de resultados ainda está no campo a inspeção, sobretudo pelo seu aspecto individualizado.

Os/a docentes entrevistados/a reconhecem o papel fundamental da avaliação institucional colabora tanto na melhoria das condições da escola em cumprir o seu papel social quanto (Professores B do Ensino Primário), para tanto destacam a importância de se investir neste instrumento, preparar os/as professores/as e definir critérios objetivos à luz dos princípios que regem a educação básica (Professores A do Ensino Primário). Assim, se percebe que no contexto escolar angolano faz-se necessário desenvolver instrumentos para uma avaliação interna que permita

a reformulação das práticas pedagógicas, a melhoria da comunidade e das relações humanas. Mostra os pontos fortes e fracos e permite a correção e aperfeiçoamento da trajetória a ser seguida por todos os envolvidos na comunidade escolar" (MOURA, 2017, p. 59).

Por fim, em relação ao papel da comunidade na avaliação da escola, os/a professores/a compreendem e valorizam a participação das famílias nas atividades escolares.

- É de ajudar a melhorar as falhas da escola (Professores B do Ensino Primário);

- A comunidade tem participado nas decisões da escola, sobretudo quando há uma irregularidade (Professores $\mathrm{C}$ do I Ciclo);

- O papel da comunidade na avaliação durante os sete anos a sociedade não contribui, as comissões não aderem aos convites, muitos não acompanham os filhos e só reclamam se o filho reprovar (Professores D do I Ciclo);

- A comunidade tem um papel importante na avaliação da escola, porque eles ajudam os professores com as suas ideias (Professores E do II Ciclo); 
- Os pais e encarregados de educação ajudam à escola no desenvolvimento dos valores morais (Professores F do II Ciclo).

Também reconhecem que para muitas famílias a participação na vida escolar de suas crianças e adolescentes é dificultada pelas condições sociais em que vivem, tal como expressa o Docente A do Ensino primário: "papel da comunidade na avaliação da escola tem como objetivo ajudar a direção da escola, o pai tem que acompanhar o filho, há pais que vêm na escola no tempo das confirmações de matrícula, porque só se dedicam à lavra".

As respostas apresentadas pelos/a professores/a levam a perceber consideram a avaliação de uma instituição como elemento fundamental tanto para o ensinoaprendizagem dos alunos quanto para que a escola atinja os seus objetivos. Entretanto, se nota que carece ainda, no contexto educacional angolano, de instrumentos avaliativos que superem a "lógica de inspeção", isto é, que não cumpram somente o papel de aferir individualmente a adesão de docentes a um programa de ensino, mas que permita uma análise global da unidade escolar.

\section{Considerações finais}

A realização do processo de avaliação institucional em educação precisa comportar a complexidade que envolve comporta tem envolve a escola: desempenho docente, materiais didáticos, estratégias de ensino e aprendizagem, programas e currículos, a gestão, estrutura material da escola, as condições de trabalho dos profissionais e a relação da unidade escolar com a comunidade envolvente. Portanto, não se pode tratar de uma realidade descontextualizada.

Isto significa que os instrumentos têm que ser diversificados, de modo a permitir a triangulação dos dados, melhor abrangência, objetividade e imparcialidade. Para além das definições das metas individuais ou coletivas a serem alcançadas é preciso ter sempre presente os objetivos da educação escolar e o papel social que a escola desempenha no processo de conformação de uma sociedade mais justa e igualitária. 
Artigos | Percepção docente sobre a avaliação interna no ensino geral angolano (UARINHENGA, Balbina; OLIVEIRA, Rosenilton Silva de)

No contexto angolano, do ponto de vista legislativo, a avaliação institucional surge no contexto da segunda Reforma Educativa (Lei № 13/01) no final do conflito armado que perdurou por quase uma década após a independência nacional, em 1975. Por meio do Decreto-Lei no 17/2016, promulga-se a nova Lei de Bases do Sistema de Educação e Ensino (LBSEE), revogando o dispositivo de 2001 e reafirmando o compromisso de se desenvolver uma educação escolar que prima pelo desenvolvimento integral do sujeito e consolide a justiça social, o humanismo e a democracia pluralista.

A nova LBSEE, procura aperfeiçoar um processo iniciado em 1975, ano da independência, quando rompe-se com o modelo escolar colonial (LIBERATO, 2014). Isto significou um investimento tanto na expansão da oferta de vagas na educação básica quanto na criação de novas instituições de ensino superior em todas as regiões do país. Há, portanto, um processo em curso que tem paulatinamente vencido alguns desafios, enquanto outros se impõe.

Quanto às percepções sobre a avaliação institucional, destacam-se alguns posicionamentos docente que tendem a reduzir às ações pontuais de análise curricular ou metodológica em detrimentos de uma natureza integradora e sistémica da avaliação. De certa forma, isto se porque ainda não se percebe no contexto da educação básica angolana o desenvolvimento de instrumentos que permitam romper com a lógica inspetoral e normativa da avaliação. Dito de outro modo, até o momento houve um investimento por parte do Estado em estabelecer critérios e métodos de aferição do desempenho docente em relação à aplicação dos programas de ensino pré-definidos, carece, entretanto, do estabelecimento de práticas avaliativas (internas e externas) que supere esta postura fiscalizadora, que seja capas de, por um lado, apontar os desafios e, por outro, propor soluções criativas e coletivas.

Se argumentou que no caso em tela, uma vez que no atual Sistema Geral de Ensino Angolano (cuja reforma deu-se em 2016) ainda está em processo de configuração e não conta com processo avaliativos institucionais definidos, os professores atribuem múltiplos sentidos ao ato de avaliar sem, no entanto, relacioná-lo com a própria estrutura da instituição escolar. Isto significa dizer que embora haja a percepção de que cabe a todos os agentes (estudantes, docentes, equipe gestora, familiares etc.) a consecução dos objetivos previstos para a educação escolar, os instrumentos 
Artigos | Percepção docente sobre a avaliação interna no ensino geral angolano (UARINHENGA, Balbina; OLIVEIRA, Rosenilton Silva de)

avaliativos existentes até o momento têm reforçado as responsabilidades individuais dos/as professoras. e não propriamente coletivas.

Por fim, conforme apontou-se ao longo do texto, não se trata de substituir um modelo avaliativo por outro, mas compor uma constelação de métodos capazes de aferir as múltiplas dimensões da realidade escolar e seus objetivos enquanto espaço de produção de dispositivos para superação das desigualdades.

\section{Referências}

AFONSO, A. Políticas educativas em Portugal (1985-2000): a reforma global, o pacto educativo e os reajustamentos neo-reformistas. In A.M. Catani ; R. P. Oliveira (orgs.), Reformas Educacionais em Portugal e no Brasil. Belo Horizonte: Autêntica, pp. 17-40. 2000

ANGOLA. Constituição da República de Angola, 2010. Disponível em: https://www.wipo.int/edocs/lexdocs/laws/pt/ao/ao001pt.pdf Acesso em 23 de novembro de 2020. Resultados Preliminares do Recenseamento Geral da População e habitação. Luanda: INE, 2016.

FIALHO, Ismael José; NOBREGA, Paulo Jorge. O perfil do inspetor e o efeito da inspeção da educação no desempenho docente. Um estudo em escolas do II ciclo do ensino secundário no município da Chibia (Angola). Revista Educação: Temas e Problemas, 16. 2016, pp 1-18.

FREIRE, Paulo. Pedagogia da Indignação: cartas pedagógicas e outros escritos. São Paulo: Ed. UNESP, 2000.

IZA, Juliana Gama. O Ensino Superior em Angola e no Brasil: A Cooperação Acadêmica entre a Universidade Lueji A'Nkinde (ULAN) e a Faculdade de Educação da Universidade de São Paulo (Feusp). São Paulo: Universidade de São Paulo, 2018. Tese de Doutorado. Disponível em: http://www.teses.usp.br/teses/disponiveis/48/48134/tde-10022017-132543/pt-br.php

Lei № 17/16, de 7 de Outubro. Lei de Bases do Sistema de Educação - Diário da República. Assembleia Nacional I Série no 170

LIBERATO, Ermelinda. Avanços e retrocessos da educação em Angola. Revista Brasileira de Educação v. 19 n. 59 out.-dez. 2014, pp 1003-1031.

LUBALO. Relatório - ADMINISTRAÇÃO MUNICIPAL DO LUBALO, 2007.

LÜCK, Heloísa. Dimensões de Gestão Escolar e suas Competências. Curitiba, Editora Positivo, 2009.

MANASSA, João Baptista Abreu. Lunda: história e sociedade. Belas: Mayamba, 211.

MARINELLI, M. Autoavaliação institucional: estudo de sistemas de educação corporativa em bancos de desenvolvimento brasileiros. Tese apresentada para obtenção do título de Doutor em Educação. Faculdade de Educação, da Universidade Federal do Ceará, 2013.

MOURA, Marcelo Pinto Coelho. Avaliação Institucional como Instrumento de Gestão Estratégica: estudo de caso em uma escola estadual de Itabira - MG/Dissertação MP Universidade Federal de Juiz FE/ CAEd. P. Pós Graduação em Gestão e Avaliação da Educação 2017 
Artigos | Percepção docente sobre a avaliação interna no ensino geral angolano (UARINHENGA, Balbina; OLIVEIRA, Rosenilton Silva de)

PATTON, M.Q. Ouatitative Evaluation. Beverly Hills: SAGE, 1980.

VASCONCELLOS, Celso Dos S. Avaliação Escolar. São Paulo, Cortez. 7a Edição. 1998

VICTORINO, Samuel Carlos. O papel da educação na reconstrução nacional da República de Angola. Revista Diálogos: pesquisa em extensão universitária. IV Congresso Internacional de Pedagogia Social: domínio sociopolítico. Brasília, v.17, n.1, jun, 2012.

ZAU Manuel. Processo da Avaliação da Qualidade de Ensino Superior em Angola. Luanda: Edições Eco7, 2 ed.. 2019. 